\title{
Clear cell carcinoma of salivary gland type presenting as an endotracheal polypoid tumor
}

\author{
Kazuhiro Tabata ${ }^{1,2^{\star}}$, Michiyo Higashi ${ }^{2}$, Shinichi Kitajima ${ }^{3}$, Ikumi Kitazono ${ }^{2}$, Tsubasa Hiraki ${ }^{2}$, \\ Tsunayuki Otsuka ${ }^{4}$, Masaya Aoki ${ }^{4}$, Kazuhiro Wakita ${ }^{4}$, Hirofumi Nakayama ${ }^{5}$, \\ Suguru Yonezawa ${ }^{2}$, Junya Fukuoka ${ }^{6}$ \\ ${ }^{1}$ Laboratory of Pathology, Nagasaki University Hospital, Nagasaki, Japan; \\ *Corresponding Author: t-kaz@nagasaki-u.ac.jp \\ ${ }^{2}$ Department of Human Pathology, Kagoshima University Graduate School of Medical and Dental Sciences, Kagoshima, Japan \\ ${ }^{3}$ Department of Pathology, Kagoshima University Hospital, Kagoshima, Japan \\ ${ }^{4}$ Department of General Thoracic Surgery, Kagoshima University Graduate School of Medical and Dental Science, Kagoshima, \\ Japan \\ ${ }^{5}$ Department of Radiology, Kagoshima University Graduate School of Medical and Dental Sciences, Kagoshima, Japan \\ ${ }^{6}$ Department of Pathology, Nagasaki University Graduate School of Biomedical Science, Nagasaki, Japan
}

Received 2 March 2013; revised 20 April 2013; accepted 4 May 2013

Copyright (C 2013 Kazuhiro Tabata et al. This is an open access article distributed under the Creative Commons Attribution License, which permits unrestricted use, distribution, and reproduction in any medium, provided the original work is properly cited.

\section{ABSTRACT}

A 66-year-old woman presented with a 2-year history of asthma has progression of dyspnea within a week, and a computed tomography (CT) revealed an endotracheal tumor at level of aortic arch. The resected tumor, measured by $18 \times$ $12 \times 10 \mathrm{~mm}$, has histologically malignant features including frank invasion with desmoplastic stroma and foci of necrosis. Presence of glycogen and mucin was confirmed by periodic acid-Schiff (PAS) and diastase PAS staining. Immunohistochemically, the tumor cells were diffusely positive for cytokeratin (CK) 7 and AE1/3, focally positive for $\mathrm{CK}_{5} / 6$ and $\mathrm{CK} 14$, but negative for CK20. Thyroid transcription factor-1 (TTF1), Napsin A, and SP-A, indicating lung parenchymal origin were all negative. Other muscular markers, neuroendocrine markers, renal cell carcinoma markers, and markers related to perivascular epithelioid cell tumors were all negative. Postoperative systemic examination suggests no primary tumor outside the lung. The follow up was excellent being recurrence free for 14 months in spite of the positive surgical margin by the tumor cells. This is a first report of rare neoplasm, clear cell carcinoma of salivary gland type, presenting as an endotracheal mass.

Keywords: Clear Cell Carcinoma; Salivary Gland; Lung Primary; Histological Feature

\section{INTRODUCTION}

Malignant clear cell tumor can occur in any organs, especially kidney and female genital tract in primarily, but the tumor of the lung is extremely rare. In lung, differential diagnosis of so called "clear cell tumors" include benign clear cell tumor (sugar tumor), clear cell carcinoma (variant of large cell carcinoma), clear cell adenocarcinoma, clear cell variant of squamous cell carcinoma (SCC), metastatic carcinoma.

In this report, we present a case of endotracheal clear cell carcinoma of salivary gland type and discuss the clinical and pathological importance and its challenging diagnostic points with the review of literatures.

\section{CASE REPORT}

\subsection{Clinical Findings}

A 66-year-old woman was admitted to a hospital because of progressive dyspnea. She had a history of asthma for 2 years. A computed tomography revealed a tumor almost obstructing the trachea at level of aortic arch (Figures 1(a) and (b)). Emergency operation was performed with only evaluation of cardiac function. Rigid tracheoscopy revealed the endotracheal pedunculated tumor with smooth surface and nearly complete obstruction of the trachea (Figure 2). The tumor was resected at stalk by snare ablation and was taken out as much of the tumor as possible, additionally, argon plasma coagulation was performed at excisional margin.

Clinically and histologically, surgical margin of the tumor was positive. The patient denied additional resec- 


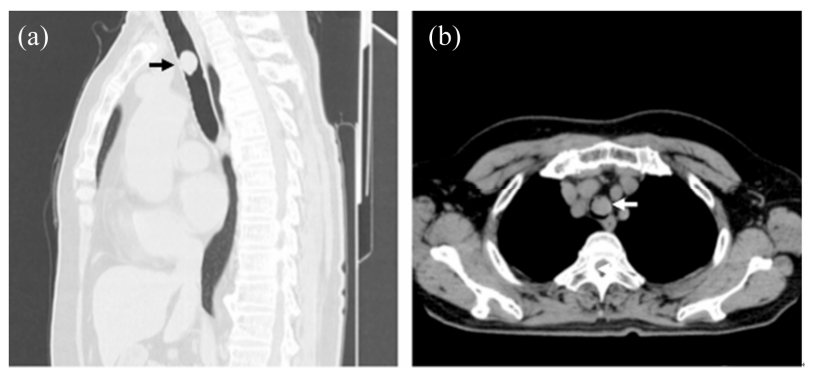

Figure 1. Computed tomography (CT) appearance of the tumor. (a) Sagital section of chest CT. Black arrow points the tumor; (b) Horizontal section of Chest CT. White arrow points the tumor. The tumor markedly obstructs the trachea at level of aortic arch.

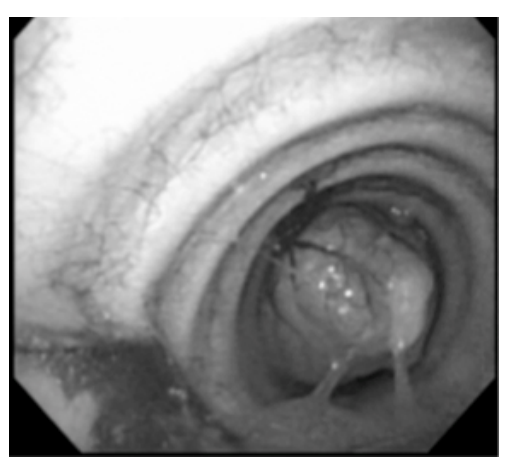

Figure 2. Tracheoscopy appearance of the tumor. Endotracheal pedunculated tumor with smooth surface obstructs the trachea.

tion, then the follow-up without any therapeutic procedure was taken place. Postoperative CT and Positron emission tomography (PET) discovered no mass lesion in the other sites of the lung. 14 months postoperative bronchoscopy revealed no local recurrence or metastatic lesion.

\subsection{Pathological Findings}

Grossly, the size of the resected tumor was $18 \times 12 \times$ $10 \mathrm{~mm}$. The surface was smooth and yellowish-white along with focal hemorrhage (Figure 3(A)). Histologically, the tumor was covered with normal ciliated epithelium and it composed of monotonous clear cells which forming solid and trabecular patterns with sparse glandular structure. Desmoplastic stroma associated with stromal invasion and foci of necrosis were seen. The tumor cells had abundant clear cytoplasm, mild enlarged nuclei without prominent nucleoli, and mitotic figure was rare (1/10 HPF) (Figures 3(B)-(D)).

Histochemically, the tumor cells contained sparse intracytoplasmic glycogen and mucin confirmed by periodic acid-Schiff (PAS) and diastase-PAS stains, respectively (Figures 3(E) and (F)). PTAH staining was negative. Immunohistochemically, the tumor cells were posi-
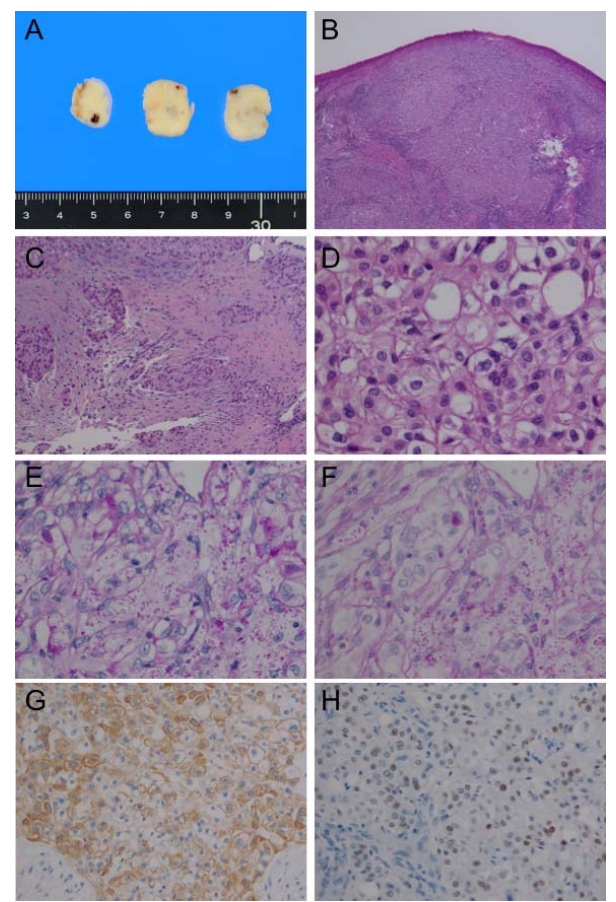

Figure 3. Pathological appearance of the tumor. (A) Gross appearance of the cur surface shows yellowish-white color with focal hemorrhage. (B) The tumor was covered by normal ciliated epithelium, and monotonous clear cells formed solid and trabecular patterns (H \& E stain, 2×); (C) Focal invasion with desmoplastic reaction. (H \& E stain, 10×); (D) Tumor cells have abundant clear cytoplasm, mildly enlarged nuclei without prominent nucleoli. Mitosis is not found. (H \& E stain, 40×); (E) Periodic acid-Schiff (PAS) stain, 40×; (F) Diastase-PAS stain, 40×; (E) and (F) show both intracytoplasmic glycolgen and mucin; (G) Immunohistochemical staining for Cytokeratin 7 shows cytoplasmic staining for the tumor cells $(\times 10)$; $(\mathrm{H})$ p53 staining shows various nuclear staining including some strong signal suggesting possible overexpression.

tive for vimentin, cytokeratin (CK) 7, and pancytokeratin (AE1/AE3 and CAM5.2) (Figure 3(G)), and focally positive for CK5/6, CK14, and p63, but negative for CK20, carcinoembryonic antigen (CEA), thyroid transcription factor-1 (TTF-1), Napsin A, SP-A, smooth muscle actin (SMA), neuroendocrine markers (CD56, synaptophysin and chromogranin A), S100, HHF35, HMB45, Melan A, Glial fibrillary acidic protein (GFAP), CD68, CA125, Ber-EP4, CD10, and RCC. p53 staining showed positive signals with possibly focal overexpression in the nuclei of the tumor cells (Figure 3(H)). MIB-1 labeling index was approximately $5 \%$. Based on the morphology and histochemical and immunohistochemical staining results, the diagnosis of clear cell carcinoma of salivary gland type was made. Despite the result of surgical margin be- 
ing positive for the tumor cells, no recurrence has been identified within 14 months' follow up by bronchoscopy and CT.

\section{DISCUSSION}

Lung cancer of salivary gland type is a rare malignant neoplasm occurring approximately $0.1 \%$ to $1 \%$ of the lung cancer [1,2]. Clear cell change may occur in the true salivary gland neoplasm, but the frequency is rare and at the best of our knowledge, this is a first report of the case presenting in the lower respiratory system. On the other hand, lung cancer with abundant clear cell component also occurs in the rare fashion. Katzenstein et al. [3] retrospectively examined 348 resected cases of lung cancer and found that case occupied by clear cells for more than $90 \%$ and $50 \%$ of whole tumor was in one and 15 patients, respectively. They also reported the ratios of clear cells in squamous cell carcinoma (SCC), adenocarcinoma, and large cell carcinoma being 33\%, 27\%, and $71 \%$, respectively and that the prognosis of clear cell carcinoma was depend on the coexistent subtypes. According to the WHO classification, 4th edition, pure clear cell carcinoma is defined as subtypes of large cell carcinoma and when definite glandular or squamous differentiation are identified, the diagnoses of clear cell adenocarcinoma or clear cell variant of SCC will be given [4].

For the present case, differential diagnosis including carcinoid tumor, clear cell carcinoma of salivary gland type, clear cell tumor (alternatively named sugar tumor), clear cell adenocarcinoma, clear cell carcinoma (subtype of large cell carcinoma), clear cell variant of SCC, and metastatic tumor, especially renal cell carcinoma, were considered. The systemic examination after the surgery other organs.
By the immunohistochemical staining, we limited the differential diagnosis to either clear cell carcinoma of salivary gland type or clear cell adenocarcinoma of the lung parenchymal origin [5]. Immunohistochemical staining profile was not conclusive for a definite diagnosis between the two diagnoses, however, none supported the tumor was originated from lung parenchyma. Biologically, clear cell carcinoma of salivary gland type is a tumor of borderline malignancy whilst the clear cell adenocarcinoma of lung parenchyma is a truly malignant neoplasm usually being lethal. Due to the location and gross of endotracheal mass, clear cell carcinoma of Salivary gland type was compelled.

Interesting point is about the histological invasiveness of the current case along with the presence of necrotic foci and the presence of p53 overexpression. They indicated histologically high grade neoplasm which is an unusual feature for the clear cell carcinoma of salivary gland type.

Clear cell carcinoma of the salivary gland, alternatively named clear cell carcinoma, not otherwise specified (NOS), is a rare tumor which shows monomorphous population of cells with optically clear cytoplasm and lacks features characteristic of other salivary neoplasms such as myoepithelial origin. Clear cell carcinoma, NOS of the salivary gland is now considered as one of the glycogen-rich adenocarcinomas [6]. Yang et al. presented immunohistochemistrical study of their 4 cases where CK7, CK8/18, and CK19 were diffusely and strongly expressed in 3 cases. They also indicated that CK 5/6, 14, and 17 were focal expressed and CK10/13, S100, vimentin, smooth muscle actin, and calponin were all negative [7]. Wang et al. also summarized the staining profile of clear cell carcinoma, NOS of the salivary

Table 1. Immunohictochemical profile of clear cell carcinoma.

\begin{tabular}{|c|c|c|c|c|c|c|c|}
\hline & Cytokeratins & Epithelial & Mesenchymal & Melanocytic & Pulmonary & Neuroendocrine & Others \\
\hline Yang et al. [7] & $\begin{array}{l}\text { Diffuse ++: } \\
\text { CK7, CK8/18, CK19, } \\
\text { Focally +: } \\
\quad \text { CK5/6, CK14, CK17 } \\
\text {-: CK10/13 }\end{array}$ & np & $\begin{array}{l}\text { - } \\
\text { Simentin } \\
\text { Calponin }\end{array}$ & S100 & np & np & np \\
\hline Wang et al. [8] & np & np & $\begin{array}{l}+ \\
\text { SMA } \\
\text { Muscle specific actin } \\
\text { Calponin }\end{array}$ & $\begin{array}{l}- \\
\text { S100 }\end{array}$ & np & np & np \\
\hline Iyoda et al. [9] & $\begin{array}{l}+ \\
\text { unspecified }\end{array}$ & $\begin{array}{l}+ \\
\text { EMA }\end{array}$ & - & $\begin{array}{l}- \\
\text { HMB-45 }\end{array}$ & $\begin{array}{l}- \\
\text { PE10 }\end{array}$ & - & $\begin{array}{l}\text { - } \\
\text { Lysozyme } \\
\text { Lactoferrin } \\
\text { CEA }\end{array}$ \\
\hline Our case & $\begin{array}{l}\text { Diffuse ++: } \\
\text { CK7, AE1/AE3, } \\
\text { CAM5.2 } \\
\text { Focally +: } \\
\text { CK5/6, CK14 } \\
\text {-; CK20 }\end{array}$ & - & $\begin{array}{l}+ \\
\text { Vimentin } \\
- \\
\text { SMA } \\
\text { HHF35 }\end{array}$ & $\begin{array}{l}- \\
\text { HMB-45 } \\
\text { Melan A } \\
\text { S100 }\end{array}$ & $\begin{array}{l}- \\
\text { TTF-1 } \\
\text { SP-A } \\
\text { Napsin A }\end{array}$ & $\begin{array}{l}\text { - } \\
\text { CD56 } \\
\text { Chromogranin A } \\
\text { Synaptophysin }\end{array}$ & $\begin{array}{l}- \\
\text { CEA, CA125, } \\
\text { CD10, CD68, } \\
\text { GFAP, RCC }\end{array}$ \\
\hline
\end{tabular}

CK: cytokeratin; EMA: epithelial membrane antigen; SMA: smooth muscle actin; TTF-1: thyroid transcription factor 1; CEA: carcinoembryonic antigen; np: not performed. 
gland, where smooth muscle actin, muscle specific actin, and calponin being positive and S100 being negative, respectively [8]. There is no definite diagnostic marker of this tumor, however, location and the negative immunohistochemical results of other tumor especially markers of pulmonary adenocarcinoma are important. Immunohistochemical profile in the comparison with those manuscripts and the current case was indicated in Table 1. Iyoda et al. confirmed their case for adenocarcinoma by special staining and electron microscopy [9], however, we think the tumor they presented still can be a clear cell carcinoma of salivary gland type as our case. Due to the large difference of clinical behavior, accumulation of data for the similar cases is important.

\section{REFERENCES}

[1] Moran, C.A. (1995) Primary salivary gland-type tumors of the lung. Seminars in Diagnostic Pathology, 12, 106122.

[2] Heitmiller, R.F., Mathisen, D.J., Ferry, J.A., Mark, E.J. and Grillo, H.C. (1989) Mucoepidermoid lung tumors. Annals of Thoracic Surgery, 47, 394-399. doi:10.1016/0003-4975(89)90380-9

[3] Katzenstein, A.L., Prioleau, P.G. and Askin, F.B. (1980) The histologic spectrum and significance of clear-cell change in lung carcinoma. Cancer, 45, 943-947. doi:10.1002/1097-0142(19800301)45:5<943::AID-CNCR 2820450518>3.0.CO;2-7

[4] Travis, W.D., Blambilla, E., Kornrad Muller-Hermelink, H.K. and Harris, C.C. (2004) WHO classification of tu- mours. Pathology and genetics of tumours of the lung, pleura, thymus and heart. IARC Press, Lyon.

[5] Whithaus, K., Fukuoka, J., Prihoda, T.J. and Jagirdar, J. (2012) Evaluation of napsin A, cytokeratin 5/6, p63, and thyroid transcription factor 1 in adenocarcinoma versus squamous cell carcinoma of the lung. Archives of $\mathrm{Pa}$ thology \& Laboratory Medicine, 136, 155-162. doi:10.5858/arpa.2011-0232-OA

[6] Barnes, L., Eveson, J.W., Reichart, P. and Sidransky, D. (2005) World Health Organization classification of tumours. Vol. 9: Pathology and genetics of tumours of the head and neck. IARC Press, Lyon.

[7] Yang, S., Zhang, J., Chen, X., Wang, L. and Xie, F. (2008) Clear cell carcinoma, not otherwise specified, of salivary glands: A clinicopathologic study of 4 cases and review of the literature. Oral Surgery, Oral Medicine, Oral Pathology, Oral Radiology \& Endodontics, 106, 712-720. doi:10.1016/j.tripleo.2008.04.016

[8] Wang, B., Brandwein, M., Gordon, R., Robinson, R., Urken, M. and Zarbo, R.J. (2002) Primary salivary clear cell tumors-A diagnostic approach a clinicopathologic and immunohistochemical study of 20 patients with clear cell carcinoma, clear cell myoepithelial carcinoma, and epithelial-myoepithelial carcinoma. Archives of Pathology \& Laboratory Medicine, 126, 676-685.

[9] Iyoda, A., Hiroshima, K., Toyozaki, T., Tsukamoto, Y., Haga, Y., Fujisawa, T. and Ohwada, H. (2000) Clear cell adenocarcinoma with endobronchial polypoid growth. Pathology International, 50, 979-983. doi:10.1046/j.1440-1827.2000.01140.x 